\title{
DIVISION II: SUN AND HELIOSPHERE
} (SOLEIL ET HELIOSPHERE)

\author{
PRESIDENT: Arnold O. Benz \\ BOARD: Donald B. Melrose, Sami K. Solanki, Tom J. Bogdan, Marek Van- \\ das, David F. Webb, Peter V. Foukal \\ Commission 10: Solar Activity \\ Commission 12: Solar Radiation and Structure \\ Commission 49: Interplanetary Plasma and Heliosphere
}

The fields of solar and heliospheric physics were strongly represented at the IAU General Assembly in Sydney. A Symposium "The Stars as Suns: Activity, Evolution and Planets" organized jointly with the stellar Division IV attracted many participants. Three Joint Discussions were held the week before on "Magnetic Fields and Helicity in the Sun and Heliosphere", "The Sun and the Heliosphere as an Integrated System" and "Solar and Solar-like Oscillations: Insights and Challenges for the Sun and Stars". Thus there was no need to have further scientific meetings organized by Division II.

On July 21, 2003, an open business meeting was held in the course of the General Assembly lasting all morning. About 60 members attended. The meeting was followed by business meetings of the three commissions. As there was no objection from the members, the commission meetings were held in succession after the coffee break and were attended by a similar number of colleagues. This report summarizes the discussions and conclusions.

\section{Reorganization of the Division}

The new statutes and by-laws of the IAU are emphasizing the role of divisions and reducing the importance of commissions. Commissions can be created, renamed or dissolved by the division. Their main function is to allow sub-communities of the division to organize themselves and to voice their interest. The existence of a commission must now be justified every three years to avoid fossilization. Working groups can be created and changed by the division or a commission. They have to be approved by the division and by the EC.

The aims of the three commissions in Division II justify their existence: Commission 10 focuses on transient aspects, including flares, CMEs, particle acceleration, reconnection, shocks in the corona, microflares and their impact on coronal heating. Commission 12 emphasizes the steady-state aspects, including helioseismology, magnetic field generation (dynamo), active regions, solar irradiance, photosphere, and chromosphere. The fields covered by Commission 49 are the solar wind, transient and corotating structures of the heliosphere. However, there is considerable overlap, such as e.g. magnetic activity, space weather or solar evolution. In such cases, the Division may take the initiative. From the IAU point of view, all that can be done at the Division level should be a division affair. However, many new initiatives may originate in the commissions and some will be carried out at their level. 
New procedures for the selection or election of presidents and organizing committees for divisions and commissions result from the new statutes. The organizing committee (OC) of Division II will include the president and vice-president of the division, and the presidents and vice-presidents of the 3 commissions of Division II. A secretary may be designated from among the OC of Div II if needed.

The division president is now elected by the general assembly on the proposal of the EC. The EC proposes after receiving an appropriate proposal by the division. Thus Division II had to discuss and approve new election procedures for selecting a candidate for division president. They are as following:

\subsection{Selection of Division President}

- Each member of Division II shall be invited to propose a candidate for the new vice-president one year ahead of the General Assembly.

- The out-going Organizing Committee of Division II votes for the new president and vice-president from the proposed candidates. Traditionally, the former vicepresident becomes the new president. The new vice-president must be from a different continent than the current VP.

- The new Organizing Committee of Division II consists of the in-coming president and vice-president of the Division II, the presidents and vice-presidents of Commissions 10, 12 and 49, plus the out-going president of the Division.

- The new Organizing Committee may elect a secretary from among its members.

- The Executive Committee of the IAU confirms the selection (required by IAU) and proposes it to the General Assembly who elects the division presidents.

\subsection{Confirmation of Division OC, President and Vice-president}

The proposed new Division OC, president and vice-president were presented by the vice-president. They were confirmed by the attending members.

\section{Working Groups}

The IAU Working Group on "Solar Eclipses" headed by Jay M. Pasachoff has provided information and coordination over the last triennium for total solar eclipses in 2001 in Africa and 2002 in Africa and Australia and for annular eclipses in 2001 in Costa Rica and 2002 in Mexico, as well as for the partial phases that were visible for thousands of kilometers to the sides. To do so, they maintain a Web site at http://www.totalsolareclipse.net. They coordinate with the Program Group on Public Education at the Time of Solar Eclipses of IAU Commission 46 on Education and Development, which has an overlapping Web site at http://www.solareclipses.info.

Members include Jay M. Pasachoff (USA, Chair), Iraida Kim (Russia), Hiroki Kurokawa (Japan), Jagdev Singh (India), Vojtech Rusin (Slovakia), Fred Espenak (USA), Jay Anderson (consultant on weather, USA), and Glenn Schneider (USA). Francis Podmore (Zimbabwe) and Frederic Clette (Belgium) were members during 2000-2003, and Atila Ozguc is a member during 2003-2006, since the next land-based total solar eclipse crosses Turkey. The work of the WG is highly appreciated by Division II for its accuracy and efficiency.

The IAU Working Group on "Solar Interplanetary Nomenclature" headed by Ed Cliver has started to publish on terms in solar and heliospheric physics that are often used in different ways leading to misunderstandings. Four articles have appeared in 
EOS, a weekly journal of the American Geophysical Union, over the past three years. They are available through links provided at the Division II home page at http://iau.org The activities of the WG were proposed for extension with many thanks for the work in the past three years.

The IAU Working Group on "Solar Data Distribution" presided by K. Shibasaki has achieved its two goals of (i) the Web publication of the remaining data in the former Quarterly Bulletin and (ii) a Web based list of solar data available through the internet: List of International Solar Archives (LISA). The page has been kindly put together by Helen Coffee. It can be found from links provided at the Division II home page at http://www.iau.org/IAU/Organization/divcom/div2.html

A new working group on "International Solar Data Access" has been founded to expand into new fields. Its duty is to coordinate the efforts made on virtual solar observatories and to include heliospheric and space weather data sources . The president of the working group is Robert Bentley (UK). The working group will include representatives from all solar virtual observatories, two members of the International Virtual Observatory (night-time) and other people involved in solar data exchange.

A new working group for "International Collaboration on Space Weather" was founded to coordinate the many activities from an IAU point of view and at an international level. It is presided by the incoming president of Division II, David Webb. One of the goals of the working group is to organize an International Heliospheric Year in 2007 initiated by N. Gopalswamy and J. Davila. IHY is aimed at producing scientific results by close international cooperation on observations and data analysis.

\section{Reports}

The status of the journal "Solar Physics" has been reviewed by O. Engvold. He informed the meeting on a recent vivid email discussion by the editorial board. Quality control has been improved in the past years but still depends strongly on the referees. The journal is sufficiently recognized by the international community as demonstrated in surveys of its impact factor. The format of volume was criticized as being too small. It is, however, specified by the publisher.

R. Thompsen from IPS Sydney delivered a report on the International Solar Energy Society (ISES) and regional heliospheric warning centers, and B. Schmieder informed the audience about Climate And Weather of the Sun-Earth System (CAWSES), taking place 2004 to 2008. CAWSES is a new initiative by SCOSTEP to investigate the SunEarth relations.

\section{Miscellaneous}

A web-based list of future conferences involving solar and heliospheric physics has been proposed. Such lists have existed on Commission web sites. A joint list is desirable that is accessible from the IAU home page.

\section{Commissions}

The elections of commission Organizing Committees had to be adapted to the new rules. In the Division meeting, Commission 10 proposed a procedure, which was discussed and then adopted by the other commissions. 


\subsection{Election of Commission Vice-president and Selection of Commission OC}

- Each member of a Commission is invited to propose candidates for the Organizing Committee of the Commission and its new vice-president one year ahead of the General Assembly.

- The Organizing Committee votes for the new vice-president from the proposed candidates. Traditionally, the out-going vice-president is confirmed by the OC as the in-coming president. The new vice-president must be from a different continent than the current VP.

- The in-coming president selects the new Organizing Committee of the Commission from the proposed candidates and according to the rules of the IAU, including geographical and sub-field distribution and continuity (not more than 12 persons, including the in-coming president and out-going president).

- The Organizing Committee of Division II confirms the election (required by IAU).

\subsection{Confirmation of Commission OCs, Presidents and Vice-presidents}

The three commissions have presented their proposals for new commission OCs, presidents and vice-presidents. They were all confirmed by the attending members.

Arnold O. Benz

President of the Division 